\title{
Development of a syllabus for postgraduate respiratory physiotherapy education: the Respiratory Physiotherapy HERMES project
}

\author{
Thierry Troosters ${ }^{1}$, Fabio Pitta ${ }^{2}$, Beatrice Oberwaldner ${ }^{3}$, Agnieszka Lewko ${ }^{4}$, \\ Deniz Inal-Ince ${ }^{5}$, Kathleen Grant ${ }^{6}$, Rik Gosselink$^{1}$, Chris Burtin ${ }^{7}$, \\ Margareta Emtner ${ }^{8}$, Enrico Clini ${ }^{9}$, Michelle Chatwin $^{10}$ and Sharon Mitchell ${ }^{11}$
}

Affiliations: ${ }^{1}$ Department of Rehabilitation Sciences and Respiratory Division, University Hospitals Leuven, Leuven, Belgium. ${ }^{2}$ Dept of Physiotherapy, Universidade Estadual de Londrina, Londrina, Brazil. ${ }^{3}$ Medical University of Graz, Graz, Austria. ${ }^{4}$ School of Rehabilitation Sciences, Faculty of Health, Social Care and Education, St Georges University of London, London, UK. ${ }^{5}$ Dept of Physical Therapy and Rehabilitation, Faculty of Health Sciences, Hacettepe University, Ankara, Turkey. ${ }^{6}$ Physiotherapy, Centre Hospitalier Universitaire Vaudois, Lausanne, Switzerland. ${ }^{7}$ Rehabilitation Research Centre, Biomedical Research Institute, Faculty of Medicine and Life Sciences, Hasselt University, Diepenbeek, Belgium. ${ }^{8}$ Dept of Neuroscience/Physiotherapy, Uppsala University, Uppsala, Sweden. ${ }^{9}$ Dept of Medical and Surgical Sciences, University of Modena-Reggio Emilia and Ospedale Villa Pineta, Pavullo, Italy. ${ }^{10}$ Clinical and Academic Dept of Sleep and Breathing, Royal Brompton Hospital, London, UK. ${ }^{11}$ Educational Activities, European Respiratory Society, Lausanne, Switzerland.

Correspondence: Thierry Troosters, Respiratory Division, UZ Gasthuisberg, Herestraat 49, 0\&N1 P0 Box 706, 3000 Leuven, Belgium. E-mail: thierry.troosters@med.kuleuven.be

@ERSpublications

The Respiratory Physiotherapy HERMES project aims to standardise treatment of patients within and beyond Europe http://ow.ly/L1e72

Best practice in the diagnosis and management of patients with respiratory conditions is now a multidisciplinary effort $[1,2]$. Physiotherapists engage in many aspects of the care of patients with respiratory diseases. Across a range of diseases, ages and settings, they carry out highly specialised treatments related to mucus clearance, breathing exercises, invasive and non-invasive mechanical ventilation, exercise training and rehabilitation, as well as reintegration of patients with respiratory disorders. Their tasks span from the neonatal intensive care unit to the palliative care unit of geriatric patients. Over the past decades, respiratory physiotherapists across the world have published research in all these fields feeding into the evidence base that underpins much of the care provided by these professionals. Physiotherapy practice has also evolved over the past few decades. Self-referral by service users (patients) is now possible in approximately half of the European member states of the World Confederation on Physiotherapy [3]. This requires highly trained health professionals capable of assessing, treating, referring and reintegrating patients. In patients with respiratory conditions, this is often performed in the context of a multidisciplinary team.

Physiotherapy education is not uniform across Europe and the world. Undergraduate and postgraduate programmes have undergone significant reforms towards an academic educational track (MSc and $\mathrm{PhD}$ ) over the past decades in many countries. In other countries, physiotherapy education is still largely geared

Received: March 062015 | Accepted: March 082015

Conflict of interest: S. Mitchell is an employee of the European Respiratory Society.

Copyright @ERS 2015 
towards a professional education. In a HERMES (Harmonised Education in Respiratory Medicine for European Specialists) survey, undergraduate physiotherapy education was stated to last between 1 year (3\% of the respondents) and more than 4 years (11\% of the respondents) [4]. Specific postgraduate specialisation tracks for respiratory physiotherapy were available in the countries of approximately half of the respondents and the duration of the postgraduate in respiratory physiotherapy training was more than 1 year in approximately $50 \%$ of those cases. Similarly, the curriculum of physiotherapy education geared towards the respiratory patient has been reported to be very heterogeneous. This highlights again the diversity of education across the world and the need for harmonisation of postgraduate education in respiratory physiotherapy. Such diversity in overall programme design and, specifically, respiratory physiotherapy, makes mobility of physiotherapists within Europe difficult. It also prevents a general quality label for respiratory physiotherapy. Meanwhile, such internationally accepted quality labels exist for other branches of physiotherapy, such as manual therapy [5].

The complexity of developing a truly universal curriculum is limited by the legal framework for physiotherapy. As an example, in some countries physiotherapists are working under a referral from medical doctors; whereas in other places, patients can have a direct access to physiotherapists. Clearly these extreme variants require different skills and competencies. In addition, as outlined above, the field for respiratory physiotherapy application is very broad and spans all age ranges and all lines and complexities of healthcare. Clearly identifiable areas with relatively little overlap are the fields of paediatrics and adult patients; or chronic/stable patients versus critically ill patients.

Regardless of the obstacles, the European Respiratory Society (ERS) physiotherapy group, together with the ERS leadership felt that there is a core set of knowledge, skills, attitudes and competencies that physiotherapists require in order to assess, treat and follow patients with respiratory disorders. A syllabus, summarising this core set was developed using an iterative process in consultation with a wide group of healthcare providers, the majority of whom were physiotherapists, and members of ERS. Furthermore, ERS non-members who are specialised in respiratory physiotherapy working in a number of different countries were also consulted. A total of 163 respondents were consulted in three rounds of a Delphi process. 10 modules were formulated in two tracks: adult and paediatric. Specific (optional) tracks were designed for physiotherapy in critically ill patients. An overview of the modules is provided in table 1 . Each of the modules contains three to 11 specific teaching items. The full list of syllabus items can be consulted online at http://ow.ly/zYkOD and can serve as a blueprint for organisations that engage in the development of postgraduate education in respiratory physiotherapy. A detailed overview of the methodology of the development of the syllabus is available elsewhere [6].

In the next phase of this project, each of the syllabus items will be translated into a curriculum which outlines how this content will be taught. This process is currently underway and will result in a curriculum

TABLE 1 Syllabus items

\begin{tabular}{lccc} 
& $\begin{array}{c}\text { Adult } \\
\text { non-critical }\end{array}$ & $\begin{array}{c}\text { Adult } \\
\text { critical }\end{array}$ & $\begin{array}{c}\text { Paediatric } \\
\text { (including newborn and infants) } \\
\text { critical }\end{array}$ \\
\hline $\begin{array}{l}\text { Assessment } \\
\text { Techniques for airway clearance }\end{array}$ & $\checkmark$ & $\checkmark$ & $\checkmark$ \\
Respiratory muscle assessment and training, breathing & $\checkmark$ & $\checkmark$ & $\checkmark$ \\
$\quad$ strategies and techniques for lung expansion & $\checkmark$ & $\checkmark$ & $\checkmark$ \\
Exercise and physical activity & $\checkmark$ & $\checkmark$ & $\checkmark$ \\
Pre- and post-operative physiotherapy & $\checkmark$ & $\checkmark$ & $\checkmark$ \\
Pharmacotherapy relevant to the physiotherapist & $\checkmark$ & $\checkmark$ & $\checkmark$ \\
Non-invasive ventilation & $\checkmark$ & $\checkmark$ & $\checkmark$ \\
Physiotherapy in the intensive care unit & & $\checkmark$ & $\checkmark$ \\
Mechanical ventilation for the respiratory physiotherapist & & $\checkmark$ & $\checkmark$
\end{tabular}

For the two tracks (adult and paediatric), the content of the modules may be different. The "critical" additional tracks are optional and provided for physiotherapists oriented to the treatment of critically ill patients, both adult and paediatrics. The full list of syllabus items can be consulted online at http://ow.ly/zYkOD 
for respiratory physiotherapy postgraduate education. The ambition should then be to implement the curriculum as widely as possible and hopefully also get the curriculum accepted by policy makers when they formally recognise a "respiratory physiotherapist". As discussed, a "specialisation" of some form in respiratory physiotherapy currently exists according to approximately $50 \%$ of respondents to our initial survey. With the present developments, we provide the tools to harmonise the meaning of specialisation with the ultimate scope to move the field further forward. If the syllabus were to be implemented in an MSc programme, it needs to be complemented with specific competences inherent to such an academic formation. In addition, the programme could be complemented with other courses that focus on treatment of patients with other non-communicable diseases. It is hoped that this will result in trained respiratory physiotherapists well equipped to treat and prevent chronic disease $[7,8]$.

\section{Acknowledgements}

The ERS Respiratory Physiotherapy HERMES Task Force would like to acknowledge each of the national experts who took part in the Delphi process and contributed their feedback to develop a consensus-based international syllabus in respiratory physiotherapy. Europe: Austria: Michaela Strauss; Belgium: Veronica Barbier, Michelle Norrenberg; Bulgaria: Blagoi Marinov; Croatia: Snjezana Benko; Czech Republic: Katerina Neumannova; Denmark: Linette Marie Kofod; Estonia: Karin Tammik; Finland: Tiina Kaistila; France: Adrian Morales Robles, Philippe Joud; Germany: Kathrin Suess; Greece: Eirini Grammatopoulou, Eleni Kortianou; Iceland: Harpa Arnardottir; Italy: Sara Mariani, Luciana Ptacinsky, Francesco D’Abrosca; Ireland: Claire Egan; Lithuania: Ieva Jamontaite; Malta: Stephen Montefort; the Netherlands: Sandra Jongenotter, Susanne van Riesen; Norway: Ulla Pedersen; Poland: Teresa Orlik, Roman Nowobilski; Portugal: Miguel Goncalves, Paulo Abreu, Alda Marques; Spain: Jordi Vilaró, M. Angels Cebriá I Iranzo, Rosa Josa; Sweden: Louise Lannefors, Karin Wadell; Switzerland: François Vermeulen; Turkey: Hulya Arikan, Sema Savci; Ukraine: Kateryna Tymruk; UK: Abebaw Yohannes, Bronwen Connolly, Judy Bradley, Brenda O’Neill. Outside Europe: Australia: Jennifer Alison, Lissa Spencer, Shane Patman; Argentina: Gustavo Olguin; Brazil: Sara Menezes, Verônica Parreira; Canada: Darlene Reid, Elisabeth Dean, Didier Saey; Thailand: Chulee Jones; USA: Donna Frownfelter, Thomas Kallstrom.

Further acknowledgement should also go to Julia Bott (Academic Health Science Network, UK) who was influential in preparing the initial project proposal.

\section{References}

1 Gibson GJ, Loddenkemper R, Lundback B, et al. Respiratory health and disease in Europe: the new European Lung White Book. Eur Respir J 2013; 42: 559-563.

2 Gibson J, Loddenkemper R, Lundbäck B, et al. European Lung White Book. Sheffield, European Respiratory Society, 2013.

3 Bury TJ, Stokes EK. Direct access and patient/client self-referral to physiotherapy: a review of contemporary practice within the European Union. Physiotherapy 2013; 99: 285-291.

4 Mitchell S, Pitta F, Troosters T. Standardised education and training for respiratory physiotherapists. Breathe 2013; 9: $171-174$.

5 Beeton K, Langendoen J, Maffey L, et al. Educational standards in orthopedic manipulative therapy. IFOMPT. 2008. www.ifompt.com/Educational+Standards.html Date last accessed: January 13, 2015.

6 Pitta F, Mitchell S, Chatwin M, et al. A core syllabus for post-graduate training in respiratory physiotherapy. Breathe 2014; 10: 220-228.

7 Bury T, Moffat M. Physiotherapists have a vital part to play in combatting the burden of noncommunicable diseases. Physiotherapy 2014; 100: 94-96.

8 Sykes C, World Confederation for Physical Therapy. Draft Policy Statement: Non-communicable diseases. 2015. www.wcpt.org/policy/ps-ncd Date last accessed: January 13, 2015. 